\title{
Da pedagogia da educomunicação à pedagogia na educomunicação
}

\author{
Thiago Reginaldo \\ Doutor em Educação pela Universidade do Estado de Santa Catarina (Udesc). \\ E-mail: th.reginaldo@gmail.com
}

\section{Ademilde Silveira Sartori}

Doutora em Ciências da Comunicação pela Universidade de São Paulo (USP). Professora Titular do Departamento de Pedagogia da Udesc.

E-mail: ademildesartori@gmail.com

Resumo: A Educomunicação é uma área que tem tido gradativamente mais visibilidade em instituições educacionais e suscita, portanto, articulação com a Pedagogia em pesquisas no intuito de compreender e contribuir para o paradigma educomunicativo. Nesse sentido, este estudo apresenta uma análise linguística das palavras e dos conceitos que a Educomunicação tem em seu âmbito pedagógico. A partir da reflexão teórica os autores deste artigo redefiniram terminologias e chegaram a área de interlocução denominada "Pedagogia na Educomunicação" como proposta que incorpora a Pedagogia da Comunicação, as Práticas Pedagógicas Educomunicativas (PPE) e os Ecossistemas Educomunicativos.

Palavras-chave: educomunicação; pedagogia da comunicação; prática pedagógica educomunicativa (PPE); ecossistemas educomunicativos; pedagogia na educomunicação.
Abstract: Educommunication is an area that has been gradually more visible in educational institutions, thus raising articulation with Pedagogy in studies aiming at understanding and contributing to the educommunicative paradigm. In this sense, this study presents a linguistic analysis of the words and concepts that Educommunication has in its pedagogical scope. From the theoretical reflection, we redefined terminologies, reaching a dialogue area called "Pedagogy in Educommunication", which incorporates Communication Pedagogy, Educommunicative Pedagogical Practice (EPP) and Educomunicative Ecosystems.

Keywords: educommunication; communication pedagogy; educommunicative pedagogical practice (EPP); educommunicative ecosystems; pedagogy in educommunication. 


\section{INTRODUÇÃO}

Pesquisas acadêmicas e práticas sociais revelam que a educomunicação está presente nos diferentes níveis de ensino que se desvelam desde a educação infantil até a universidade. No ensino superior há destaque para pesquisas que se desenvolvem em cursos específicos de graduação e pós-graduação em educomunicação, que geralmente têm interface com outros cursos da área de comunicação como, por exemplo, o jornalismo. Sua consequente aplicação e pesquisa na educação básica aparece representada devido sua articulação com projetos ${ }^{1}$ envolvendo os cursos superiores e a escola, e envolvem rádios ${ }^{2}$, jornais ${ }^{3}$ escolares e produções audiovisuais. Estudos que denotem características específicas da educação escolar e tenham interface com a prática pedagógica do professor referência, aqui compreendidas como Prática Pedagógica Educomunicativa (PPE), são mais recentes como, por exemplo, nos estudos de Moreira4 sobre as possibilidades das Tecnologias da Informação e da Comunicação (TIC) na educação básica, Souza ${ }^{5}$ a respeito dos desenhos animados na educação infantil e Schöninger ${ }^{6}$ das relações com as redes sociais digitais e as mídias ubíquas no ensino fundamental.

Com esse breve cenário traçado percebe-se que a educomunicação é um campo em evidência na educação escolar e, portanto, necessita de aprofundamento em pesquisas e conhecimentos que possibilitem compreender como este paradigma pode criar/transformar o ecossistema comunicativo, como a cultura contemporânea influencia as formas de se comunicar e como suas práticas aparecem nos processos de ensino e de aprendizagem. Este artigo contribui nesse sentido, visto que circunstancia alguns termos da área a partir de análise linguística e apresenta o conceito de "Pedagogia na Educomunicação" como chave das questões que envolvem as Práticas Pedagógicas Educomunicativas (PPE) e os Ecossistemas Educomunicativos. Para tanto, a estrutura do artigo foi organizada de forma que o leitor compreenda e se aprofunde nos diferentes termos e conceitos de autores que se iniciam pela "pedagogia da educomunicação" e áreas de intervenção da educomunicação para, a partir disso, traçar questionamentos, novos conceitos e relações teóricas com a área pedagógica.

\section{O CONCEITO DE PEDAGOGIA DA EDUCOMUNICAÇÃO}

O conceito de Pedagogia da Educomunicação aparece no livro de $\mathrm{Melech}^{7}$ ao se referir às complexidades pedagógicas e políticas da educação:

Entre essas áreas está a Pedagogia da Educomunicação, conceito que exige consideráveis esforços para se entender os variados aspectos teóricos e, a partir daí, materializar projetos midiático-pedagógicos que objetivem a conquista de uma educação mais humana, digna e democrática.

No entanto, apesar da compreensão ao que o autor se refere, tal conceito não parece conciso e elucidativo. A educomunicação, por ser um campo de estudos recentes, incorre o risco de apresentar uma inflação de termos e,
1. GARCIA-RUIZ, Rosa; GOZALVEZ PEREZ, Vicent AGUADED GOMEZ, J. Ignacio. La competencia mediática como reto para la educomunicación: instrumentos de evaluación. Cuad.inf., Santiago, n. 35 p. 15-27, 2014.

2. PATRÍCIO, Francisca de Marilac de Souza. Letramento no campo: o rádio educativo em um assentamento da reforma agrária no Ceará. 2010. Dissertação (Mestrado em Educação) - Universidade Federal do Ceará, Fortaleza, 2010.

3. MIRANDA, Amanda Souza de. Divulgação da ciência e educomunicação: contribuições do jornal escolar para a alfabetização científica. 2007. Dissertação (Mestrado em Educação Científica e Tecnológica) - Universidade Federal de Santa Catarina, Florianópolis, 2007.

4. MOREIRA, Patrícia Justo. TIC na escola contemporânea: possibilidades para a Prática Pedagógica Educomunicativa na Educação Básica. 2016. Tese de (Doutorado em Educação) - Universidade do Estado de Santa Catarina, Florianópolis, 2016.

5. SOUZA, Kamila Regina de. Os desenhos animados e a Prática Pedagógica Educomunicativa na educação infantil: uma aventura dialógica no estágio curricular. 2017. Tese de (Doutorado em Educação) - Universidade do Estado de Santa Catarina, Florianópolis, 2017.

6. SCHÖNINGER, Raquel ReginaZmorzenskiValduga. Educomunicação e teoria ator-rede: a tessitura de redes de aprendizagem via mídias ubíquas. 2017. Tese de (Doutorado em Educação) - Universidade do Estado de Santa Catarina, Florianópolis, 2017.

7. MELECH, Edgard C. Educomunicação. 2016. Disponível em: http://repositorio. unicentro.br:8080/ispui/bitstream/123456789/1248/47/ MELECH\%2C\%20Edgard\%20Cesar\%20-\%20 Educomunica\%C3\%A7\%C3\%A3o.pdf. Acesso em: 27 abr. 2020. p. 21. 
8. BACCEGA, Maria Aparecida. Comunicação/ educação e a construção de nova variável histórica. Comunicação \& Educação, São Paulo, ano 14, n. 3, p. 23, 2009.

9. SOARES, Ismar de Oliveira. Plano de leitura e pesquisa. In: SOARES, Ismar de Oliveira: VIANA Claudemir Edson; XAVIER, Jurema Brasil (org.). Educomunicação e suas áreas de intervenção: novos paradigmas para o diálogo intercultural. São Paulo: ABPEducom 2017. p. 14.

10. INTERVENÇÃO. In: MICHAELIS: dicionário brasileiro da língua portuguesa. São Paulo: Melhoramentos, 2020. Disponível em: http://michaelis.uol. com.br/busca?id=4bla3 Acesso em: 27 abr. 2020.

11. MARTÍN-BARBERO, Jesús. A comunicação ná educação. São Paulo: Contexto, 2014, p. 33. por consequência, a derivação semântica que leva à mistura entre o educacional e comunicativo. Aqui cabe pensar na conjunção dos termos Pedagogia e Educomunicação, que pode chegar a diferentes perspectivas. Isso será explicado no decorrer deste artigo. A Pedagogia da Educomunicação é aqui compreendida como todo o arcabouço organizacional das atividades e projetos colaborativamente organizados nas mais diferentes áreas do conhecimento com participação da abordagem educomunicativa, não somente as pedagógicas. É, portanto, área que comporta características multidisciplinares, pluridisciplinares, interdisciplinares e transdisciplinares das diversas áreas do conhecimento. Por exemplo, "Economia, Política, Estética, História, Linguagens, entre outros saberes, compõem o campo. Cada um desses saberes dialoga com os outros, e essa complexa interseção se coloca no centro das investigações desse campo" . Possibilita o trabalho nos mais variados setores que vão desde as organizações formais e não-formais nas instituições educativas, empresas, centros culturais e sociedade em geral com o desenvolvimento de práticas que garantam o direito à expressão e à comunicação dos sujeitos.

O campo da educomunicação é chamado por Soares ${ }^{9}$ de campo de intervenção social:

O termo "Área de Intervenção" foi agregado à estrutura conceitual da educomunicação já na conclusão da pesquisa do NCE/USP sobre a interface comunicação/ educação (1997-1999). Em última análise, foi a identificação de que diferentes tipos de ações vinham sendo desenvolvidas a partir de referenciais e metodologias semelhantes ou muito próximas entre si que possibilitou a identificação e a sistematização de um novo campo de conhecimento e de prática social, na América Latina. As Áreas de Intervenção asseguram a especificidade e a diversidade do novo campo frente a outras abordagens que buscam aproximar comunicação e educação.

Porém, antes de seguir na compreensão das áreas de intervenção, é necessário entender o que o termo "intervenção" significa. O dicionário Michaelis ${ }^{10}$ afirma que intervenção é o ato de intervir, tomar opiniões, interferência do Estado no domínio da economia, no sentido jurídico é algo para evitar a perturbação da ordem e violações e, no sentido médico, representa cirurgia. Tal definição suscita uma ação verticalizada, algo imediato que carece de solução e necessita, assim, de um grupo de especialistas legitimados burocraticamente com suas respostas e ações dispostos a "intervir". Isto posto, não parece que tal termo seja o mais apropriado para área da Educomunicação que apresenta um caráter eminentemente dialógico. O termo "interlocução" parece mais apropriado, como elucida o excerto de Martín-Barbero ${ }^{11}$ :

A textura dialógica se encontra tanto na textura do símbolo como na constituição da subjetividade: o eu só se torna real na reciprocidade da interlocução. Dialogar é arriscar uma palavra ao encontro não de uma ressonância, de um eco de si mesma, mas sim de outra palavra, da resposta de um outro. Daí que para fazer uma pergunta necessito assumir um pronome (eu) ao qual responde um outro (tu) e conformar o nós que faz possível a comunicação. O diálogo se tece sobre uma base de pronomes pessoais que formam a textura da intersubjetividade. 
Em continuação, as áreas de intervenção definidas por Soares ${ }^{12}$ em que o campo da Educomunicação pode ocorrer são: (1) a "educação para a comunicação" considerada a mais antiga, identificada com programas formativos denominados como Leitura Crítica da Comunicação, no Brasil; Media Education, na Europa e Educación en médios, na Ibero-América Latina; (2) a "Mediação Tecnológica na Educação"; (2) a "Gestão da Comunicação nos Espaços Educativos"; (4) a "Reflexão Epistemológica sobre o Agir Educomunicativo"; (5) as diferentes "Manifestações das Artes"; (6) a "Pedagogia da Comunicação", voltada para o agir comunicacional dialógico e participativo, no espaço da didática e das práticas de ensino; e (7) área da "Produção Midiática", implementada no âmbito de atuação dos meios de comunicação.

Nessas áreas de atuação apresentadas pelo autor a PPE pode transitar em mais de uma delas. Cabe aqui mais uma parada de reflexão para depois retornar no próximo parágrafo a discussão das áreas da educomunicação. Com a criação do curso superior de Licenciatura em Educomunicação na Universidade de São Paulo (USP) os caminhos no campo de interlocução mudaram. Agora, com o educomunicador enquanto profissional preparado especificamente para atuar em práticas educomunicativas, o campo definiu atuações, segundo página do curso da ECA/USP ${ }^{13}$, no âmbito do magistério, consultoria e pesquisa. O educomunicador é definido como um profissional que conhece suficientemente teorias e práticas da educação e os modelos e procedimentos que envolvem o mundo de produção midiática e das tecnologias para que possa exercer a docência e trabalhos de campo na interface comunicação/educação ${ }^{14}$. O profissional licenciado educomunicador também pode atuar na educação básica, porém, os pedagogos e demais licenciados que atuam nas redes de ensino formais não são educomunicadores, são profissionais que desenvolvem PPE. A preocupação deles, portanto, se desenvolve acerca de pensar as tecnologias e mídias na perspectiva da educomunicação de forma essencialmente pedagógica. A compreensão dessa diferença na atuação profissional é importante, uma vez que o campo da educomunicação se desenvolveu e continua a crescer.

Retorna-se aqui à discussão sobre as áreas de interlocução. Pode-se conceber que a pedagogia da educomunicação enquanto estrutura organizadora da conta de tais áreas que se organizam nos aspectos gerais da educomunicação na sociedade com suas atividades e projetos. Apesar da "pedagogia" aparecer, aqui entendida como superestrutura de organização, as atividades pedagógicas em si podem estar diluídas entre as áreas elucidadas. Parece que a divisão foi feita para os educomunicadores atuarem e os demais licenciados transitarem e se adaptarem como puderem. Isso, porém, não ajuda a entender com claridade o que se desenvolve na PPE e onde se pode compactar todas as descobertas pedagógicas estudadas nos últimos anos enquanto pesquisadores da educação. Nesse sentido, se propõe que a "pedagogia da comunicação" seja adicionada a uma área maior, a nova $6^{a}$ área, intitulada aqui: "Pedagogia na Educomunicação".
12. SOARES, Ismar de Oliveira. Plano de leitura e pesquisa. In: SOARES, Ismar de Oliveira; VIANA Claudemir Edson; XAVIER Jurema Brasil (org.). Educomunicação e suas áreas de intervenção: novos paradigmas para o diálogo intercultural. São Paulo: ABPEducom, 2017.

13. ECA/USP. Perguntas e respostas frequentes sobre educomunicação. Disponível em http://www. cca.eca.usp.br/faq. Acesso em: 27 abr. 2020

14. Ibidem 


\section{PEDAGOGIA NA EDUCOMUNICAÇÃO}

A pedagogia da comunicação na área da comunicação é entendida como uma formação necessária para que o comunicador leve em consideração o aspecto formativo da sua formação profissional. O jornalista, por exemplo, tem uma responsabilidade social enquanto educador, num sentido amplo da sua prática. Nesses termos, pode ser confundido com um termo específico da área do jornalismo, formação do jornalista, não tendo a amplitude que se deseja aqui atribuir ao termo. Assim, pode-se pensar no ensino da comunicação que, como elucida Melo $^{15}$, envolve os profissionais da comunicação social e pressupõe três blocos cognitivos articulados: conceitos comunicacionais, processos midiáticos e conteúdos culturais. Tais dimensões devem compor a grade curricular dos cursos de comunicação social com "diálogo permanente entre a universidade, as indústrias/serviços midiáticos e as corporações profissionais" 16 .

Ao falar em pedagogia da comunicação, Kaplún ${ }^{17}$ afirma que o diálogo entre educação e comunicação está longe de ser fluido e frutífero: "O mais frequente tem sido que a primeira (a educação) entendesse a segunda (a comunicação) em termos subsidiários e meramente instrumentais, concebendo-a tão somente como veículo multiplicador e distribuidor dos conteúdos que ela predetermina”. $\mathrm{O}$ autor continua seu pensamento ao falar dos termos totalizantes que dizem que educação e comunicação são a mesma coisa ou então, que, educar é comunicar, o que, no fim das contas, pode ser um perigo. Concorda-se com o autor nesta última observação. No entanto, percebe-se que os estudos já avançaram a ponto de a educação perceber que a comunicação é uma área que está para além da instrumental, não sendo aceitável esse posicionamento. A conjunção das áreas em educomunicação abriu novas perspectivas desse entendimento: do diálogo, da comutação e da convergência de saberes. Os profissionais assumem posturas diferentes, há, por exemplo, o educomunicador e há também o professor que realiza a PPE. Eles podem trabalhar em conjunto, mas os professores que concebem atividades e projetos com base na PPE têm autonomia, que lhes é concedida pela própria profissão docente.

Para explicar a pedagogia da comunicação, Kaplún utiliza Freinet na cons-

5. MELO, José Marques de. O ensino de Comunicação: os desafios da sociedade contemporânea. In: MATTOS, Sérgio (org.) Comunicação plural [online]. Salvador: Edufba 2007. p.17-31. Disponíve em: http://books.scielo. org/id/387/pdf/mat tos-9788523208943.pdf. Acesso em: 23 abr. 2020.

16. Ibidem, p.27.

17. KAPLÚN, Mario. Uma pedagogia da comunicação. In: APARICl, Roberto (org.). Educomunicação: para além do 2.0. São Paulo: Paulinas, 2014. p. 59-60

18. Ibidem, p. 78. trução de uma comunicação educativa. Kaplún ${ }^{18}$ resume duas premissas básicas e eixos principais que emergem dessa fecunda proposta:

(1) A apropriação do conhecimento pelos alunos se catalisa quando eles são instituídos e potencializados como emissores. Seu processo de aprendizagem é favorecido e incrementado pela realização de produtos comunicáveis e efetivamente comunicados; (2) Se educar for envolver em um processo de múltiplas interações, um sistema será mais educativo quanto mais rica for a trama de fluxos comunicacionais que souber abrir e pôr à disposição dos educandos.

Aqui tais premissas serão ampliadas. Os sujeitos da prática educativa relacional precisam ser mobilizados enquanto produtores de conhecimento ativo, crítico, com sentido e significado, para além da emissão, de modo que a compreensão ativa e dialógica possibilite o maior número de significações possíveis 
entre eles. Pensar nas aprendizagens mediadas e entranhadas em linguagens diversas da Educomunicação caminham para isso, pois os fluxos comunicacionais mediados estarão com os sujeitos intencionalmente. Portanto, a pedagogia na educomunicação, além de dar conta e envolver os aspectos da pedagogia da comunicação, aparece como a área que engloba aquilo que há se estudado nos últimos recentes anos - os projetos e atividades pedagógicas realizadas por intermédio das PPE e os Ecossistemas Educomunicativos. A pedagogia aqui é entendida, inicialmente, no sentido que explica Boutinet ${ }^{19}$ - como espaço das instituições escolares de nossa cultura caracterizadas pela organização de suas estruturas relacionais e didáticas:

[...] a pedagogia quer ser uma prática profissional com suas exigências, através da qual o professor esforça-se para acomodar sua dupla relação aos aprendizes e à didática que supostamente ensina: trata-se de encontrar os meios adequados para levar os alunos rumo à apropriação de um novo saber e rumo à realização de novas aprendizagens.

Portanto, a relação pedagógica é o que impossibilita que as atividades de ensino e de aprendizagem evoluam separadamente. O seu campo de excelência enquanto pesquisadores/professores são os centros de educação infantil, escolas, universidades ou qualquer outra instituição que esteja ocupada com a educação formal. Os sujeitos envolvidos fazem parte da comunidade escolar com destaque aos estudantes, professores, gestores educacionais, pesquisadores, entre outros. Assim, esse macrocampo - Pedagogia na Educomunicação - dá conta desses estudos e engloba conhecimentos da pedagogia da comunicação para as PPE e, além disso, pode orientar o trabalho de outros profissionais e educomunicadores que trabalham nas áreas formais e não formais de ensino.

\section{A PRÁTICA PEDAGÓGICA EDUCOMUNICATIVA}

A PPE está ancorada em uma perspectiva emancipatória e histórico-social da pedagogia crítica. Quando se articula tais teorias na escola não se pode tratar como fez Kaplún ${ }^{20}$ ao falar de códigos na comunicação. Entende-se ao que o autor se referiu na época, mas, por uma questão conceitual, se torna preciso adequar os termos na inter-relação educação e comunicação. Portanto, pode-se ter sistemas de representação perceptivos (semânticos) e sistemas de representação significativos (interpretativos). $\mathrm{O}$ primeiro facilitaria a educomunicação na introdução de termos, na adoção/adaptação de outras linguagens com o esforço de facilitar o processo de ensino e de aprendizagem. O segundo, com seu respectivo planejamento pedagógico ou projeto, ajudaria na ordem lógica dos signos, enunciados e discursos com o objetivo de favorecer a compreensão.

Já os ecossistemas educomunicativos devem ser pensados para que criem e ampliem a convivência humana e ação educomunicativa integrados. Devem favorecer o diálogo social levando em conta as potencialidades educativas e comunicativas das tecnologias e das mídias. Por isso, na escola deve-se pensar
19. BOUTINET, Jean-Pierre. Antropologia do projeto. Porto Alegre: Artmed, 2002 p. 186.

20. KAPLÚN, Mario. Una pedagogía de la comunicación (el comunicador popular). La Habana: Editorial Caminos, 2002. 
21. LÉVINAS, Emmanuel. Entre nós: ensaios sobre a alteridade. 5. ed. Petrópolis: Vozes, 2010.

22. BAKHTIN, Mikhail. Estética da criação verbal. 6. ed. São Paulo: WMF Martins Fontes, 2011.

23. DINIZ, Fábio Gerônimo Mota. Alteridade e empatia: novos paradigmas para as humanidades no século XXI? Cadernos de Campo, São Paulo, n. 19, p. 199-215, 2015

24. BUBER, Martin. Do diálogo e do diálogo. São Paulo: Perspectiva, 2014 p. 138.

25. LÉVINAS, Emmanuel. Totalidade e infinito Lisboa: Edições 70, 1980.

26. MARTÍN-BARBERO. Op. cit.

27. SOUZA. Op. Cit. na configuração dos saberes e narrativas que configurem a escrita, literatura, oralidade, musicalidade, visualidade, plasticidade, corporeidade e digitalidade.

Quanto aos substratos constitutivos da educomunicação percebe-se a presença da alteridade ${ }^{21}$ e da empatia ${ }^{22}$. Deste modo, pode-se pensar em como esses conceitos podem se integrar para que as relações humanas consigam ao mesmo tempo considerar o outro, lançar sobre ele um olhar e, também, tornar a experiência do outro mais significativa e prazerosa, ou em outras palavras, de acordo com Diniz ${ }^{23}$, o "olhar" como paradigma da alteridade e o "interferir" como paradigma da empatia. Acredita-se, portanto, que estes valores se beneficiam desses fenômenos inter-humanos. Para Buber ${ }^{24}$ a "esfera do inter-humano é aquela do face a face, do um-ao-outro; é o seu desdobramento que chamamos de dialógico". Na posição do eu deve-se encontrar recursos para o outro, estabelecer uma linguagem que possibilite ir além da existência interior, entender o rosto como algo absoluto que está presente na recusa de ser conteúdo ${ }^{25}$.

Enquanto para a análise a linguagem é um sistema de signos, para aquele que fala a linguagem é uma mediação simbólica: "massa de signos dispostos no mundo para exercer nele nossa interrogação" (Buber, 1968, p. 29). A dialética habita as "protopalavras eu-tu" como eixo em torno do qual se realiza o encontro e a possessão, a convivência e a organização. Levinas, por sua parte, oferece uma reflexão sobre os dinamismos da comunicação humana a partir da aparição do outro como "rosto" (Levinas, 1968, p. 82) que instaura ao mesmo tempo a possibilidade de minha interioridade e de minha abertura ao outro como questionamento de meus poderes. É na comunicação que os homens assumem suas palavras fazendo implodir, ao mesmo tempo, o círculo da totalidade totalitária e o da consciência solipsista. Dialogar é descobrir na trama de nosso próprio ser a presença dos laços sociais que nos sustentam. É lançar as bases para uma posse coletiva, comunitária, do mundo. A palavra não é um mundo à parte, mas faz parte da práxis do homem: "a justiça é o direito à palavra", pois é a possibilidade de ser sujeito em um mundo onde a linguagem constitui o mais expressivo lugar do "nós" 26 .

Assim, apresenta-se um ideal de relações na interlocução entre os sujeitos. Agora, com alguns dos conceitos elaborados e reconstituídos desses autores pode-se voltar aos princípios da PPE. Os princípios apresentados inicialmente por Souza ${ }^{27}$ serão reconsiderados com base na educomunicação, linguística e alfabetização. Além do todo complexo do processo educativo, pode-se considerar que a PPE tem dois princípios gerais com seus consequentes subprincípios: considera a cultura (pós)digital nas práticas socioculturais cotidianas e tem como pressuposto o estabelecimento do ecossistema educomunicativo.

O primeiro princípio considera a cultura (pós)digital nas práticas socioculturais cotidianas com a (oni)presença das mídias e tecnologias desde a infância como fator constitutivo da individualidade e coletividade do ser humano. Isso implica que as práticas pedagógicas sejam planejadas intencionalmente com, a partir e apesar de tal contexto de modo a ampliar o repertório dos sujeitos. Cabe pensar aqui, como primeiro subprincípio, quais são os discursos e sensibilidades advindos ou não do (pós)digital que transitam nas práticas pedagógicas. É fundamental 
que os professores estejam atentos às vivências e (des)interesses dos estudantes e que favoreçam a fluidez desses aspectos. O segundo subprincípio, ligado ao primeiro, trata da reflexão dos sujeitos sobre os diferentes aspectos das linguagens e suas correlações com o (pós)digital. Implica a abordagem dialética, crítica e criativa do universo atual comunicacional, por meio de práticas fundamentadas em linguagens verbais e não verbais que estimulem a (co)autoria. Deve-se ter claro nesse ponto o fundamental respeito e legitimação do universo dos sujeitos e das suas particularidades.

O segundo princípio tem como pressuposto o estabelecimento do Ecossistema Educomunicativo que implica, dessa forma, a criação e/ou ampliação de um ambiente de interações comunicacionais aberto e democrático na educação. Isso envolve pensar, primeiramente, que as práticas pedagógicas devem legitimar o diálogo por meio da opção pelo convívio humano. Logo, pensadas e planejadas de modo a promover a fomentar o encontro consigo e com o outro a partir do processo dialógico que envolve mediação cultural, expressão, participação e colaboração entre os diversos sujeitos envolvidos no quefazer educativo. O segundo ponto coloca a pensar sobre o uso pedagógico intencional de recursos tecnológicos e midiáticos para além de incluir a qualquer custo a tecnologia ou mídia em si, ou seja, importa que a prática pedagógica seja intencionalmente planejada de modo a fomentar o diálogo, a reflexão e a vivência da fruição, da estética, da curiosidade e da criatividade. O terceiro aspecto reflete a organização do espaço pedagógico que deve favorecer o encontro das pessoas através do olhar, do acolhimento, do aconchego, do trânsito, do fluir dos corpos e do diálogo. Para isso é imprescindível: estabelecer estratégias de trabalho pessoais que envolvam diferentes dinâmicas de grupo a contar com as individuais, de pequenos e grandes grupos, as coletivas e as alternadas; espaços dinâmicos mutáveis de acordo com os princípios pedagógicos das atividades e os projetos desenvolvidos. Aqui cabe pensar na direção em que explica Freire ${ }^{28}$ :

Os educadores não terão êxito atuando sozinhos, têm de trabalhar em colaboração a fim de serem bem-sucedidos na integração dos elementos culturais produzidos pelos alunos [...]. Finalmente, esses educadores têm que inventar e criar métodos com os quais utilizem ao máximo o espaço limitado de mudança possível que têm ao seu dispor. Precisam utilizar o universo cultural de seus alunos como ponto de partida, fazendo com que eles sejam capazes de reconhecer-se como possuidores de uma identidade cultural específica e importante.

O professor na PPE é visto como um intelectual transformador capaz de exercer uma autoridade emancipatória no sentido do que explicam Giroux e McLaren $^{29}$. Eles são vistos como interlocutores qualificados. Para Cosme ${ }^{30} \mathrm{o}$ interlocutor qualificado é aquele professor que estimula, negocia e cria condições para que os alunos consigam adquirir autonomia e sejam capazes de utilizar e recriar instrumentos, informações e procedimentos que lhes permitam pensar o mundo que os rodeia e agir eticamente congruentes com os valores próprios de uma sociedade democrática.
28. FREIRE, Paulo. Alfabetização: leitura do mundo, leitura da palavra. Rio de Janeiro: Paz e terra, 2011. p. 148-149.

29. GIROUX, Henry A. MCLAREN, Peter. Teacher education and the politics of engagement: The case for democratic schooling. Harvard Educational Review, Cambridge, v. 56, n. 3, p. 213-238, 1986

30. COSME, Ariana. O trabalho docente e o desafio de educar nas escolas contemporâneas: repensando a sala de aula. In: EDUCERE - CONGRESSO NACIONAL DE EDUCAÇÃO, 12., 2015, Curitiba. Anais [...]. Curitiba: PUC -PR, 2015. p. 32444-32454. Disponível em: https://educere.bruc.com.br/arquivo/ pdf2015/17204_10452.pdf Acesso em: 27 abr. 2020. 
comunicação \& educação • Ano XXV • número 2 • jul/dez 2020

\section{CONSIDERAÇÕES FINAIS}

As questões teóricas pontuadas ao longo do artigo são fruto de reflexões feitas de maneira gradual ao longo dos últimos dez anos por pesquisadores comprometidos com a Educação e com a escola pública, laica, gratuita e democrática. Foi possível perceber que a educomunicação, surgida no campo da comunicação, apresenta alguns descompassos teóricos naturais de uma área que comuta com outras diversas áreas do conhecimento. Cabe, portanto, a essas áreas específicas, denotar, por meio de suas pesquisas, quais são os pontos da educomunicação que precisam ser aprofundados, ressignificados e ampliados.

Durante o texto, além das pontuações teóricas em relação aos termos, foi apresentada a pedagogia na educomunicação e uma organização epistemológica da PPE. A área da educação que, por vezes, não é representada pedagogicamente no quadro da educomunicação, será representada a partir da pedagogia na educomunicação. Trata-se de um caminho epistemológico que absorve os fundamentos pedagógicos da educomunicação e que envolve, portanto, aspectos teóricos da comunicação e da educação.

Finaliza-se este artigo com a contribuição de que para haver a pedagogia da educomunicação é preciso haver pedagogia na educomunicação.

\section{REFERÊNCIAS BIBLIOGRÁFICAS}

BACCEGA, Maria Aparecida. Comunicação/educação e a construção de nova variável histórica. Comunicação \& Educação, São Paulo, ano 14, n. 3, 2009.

BAKHTIN, Mikhail. Estética da criação verbal. 6. ed. São Paulo: WMF Martins Fontes, 2011.

BOUTINET, Jean-Pierre. Antropologia do projeto. Porto Alegre: Artmed, 2002. BUBER, Martin. Do diálogo e do diálogo. São Paulo: Perspectiva, 2014.

COSME, Ariana. O trabalho docente e o desafio de educar nas escolas contemporâneas: repensando a sala de aula. In: EDUCERE - CONGRESSO NACIONAL DE EDUCAÇÃO, 12., 2015, Curitiba. Anais [...]. Curitiba: PUCPR, 2015. p. 32444-32454. Disponível em: https://educere.bruc.com.br/ arquivo/pdf2015/17204_10452.pdf. Acesso em: 27 abr. 2020.

DINIZ, Fábio Gerônimo Mota. Alteridade e empatia: novos paradigmas para as humanidades no século XXI? Cadernos de Campo, São Paulo, n. 19, p. 199-215, 2015.

ECA/USP. Perguntas e respostas frequentes sobre educomunicação. Disponível em: http://www.cca.eca.usp.br/faq. Acesso em: 27 abr. 2020. 
FREIRE, Paulo. Alfabetização: leitura do mundo, leitura da palavra. Rio de Janeiro: Paz e terra, 2011.

GARCIA-RUIZ, Rosa; GOZALVEZ PEREZ, Vicent; AGUADED GOMEZ, J. Ignacio. La competencia mediática como reto para la educomunicación: instrumentos de evaluación. Cuadernos.info, Santiago, n. 35, p. 15-27, 2014.

GIROUX, Henry A.; MCLAREN, Peter. Teacher education and the politics of engagement: the case for democratic schooling. Harvard Educational Review, Cambridge, v. 56, n. 3, p. 213-238, 1986.

INTERVENÇÃO. In: MICHAELIS: dicionário brasileiro da língua portuguesa. São Paulo: Melhoramentos, 2020. Disponível em: http:/ / michaelis.uol.com. br/busca?id=4bla3. Acesso em: 27 abr. 2020.

KAPLÚN, Mario. Uma pedagogia da comunicação. In: APARICI, Roberto (org.). Educomunicação: para além do 2.0. São Paulo: Paulinas, 2014. p. 59-78.

KAPLÚN, Mario. Una pedagogía de la comunicación (el comunicador popular). La Habana: Editorial Caminos, 2002.

LÉVINAS, Emmanuel. Entre nós: ensaios sobre a alteridade. 5. ed. Petrópolis: Vozes, 2010.

LÉVINAS, Emmanuel. Totalidade e infinito. Lisboa: Edições 70, 1980.

MARTÍN-BARBERO, Jesús. A comunicação na educação. São Paulo: Contexto, 2014.

MELECH, Edgard C. Educomunicação. São Paulo: Unicentro, 2016. Disponível em: http://repositorio.unicentro.br:8080/jspui/ bitstream/123456789/1248/47/MELECH\%2C\% 20Edgard\%20Cesar\% 20 -\%20Educomunica\%C3\%A7\%C3\%A3o.pdf. Acesso em: 27 abr. 2020;

MELO, José Marques de. O ensino de Comunicação: os desafios da sociedade contemporânea. In: MATTOS, Sérgio (org.). Comunicação plural [online]. Salvador: Edufba, 2007. p. 17-31. Disponível em: http://books.scielo.org/ id/387/pdf/mattos-9788523208943.pdf. Acesso em: 23 abr. 2020.

MIRANDA, Amanda Souza de. Divulgação da ciência e educomunicação: contribuições do jornal escolar para a alfabetização científica. 2007. Dissertação (Mestrado em Educação Científica e Tecnológica) - Universidade Federal de Santa Catarina, Florianópolis, 2007.

MOREIRA, Patrícia Justo. TIC na escola contemporânea: possibilidades para a prática pedagógica educomunicativa na educação básica. 2016. Tese (Doutorado em Educação) - Universidade do Estado de Santa Catarina, Florianópolis, 2016. 
PATRÍCIO, Francisca de Marilac de Souza. Letramento no campo: o rádio educativo em um assentamento da reforma agrária no Ceará. 2010. Dissertação (Mestrado em Educação) - Universidade Federal do Ceará, Fortaleza, 2010.

SCHÖNINGER, Raquel Regina Zmorzenski Valduga. Educomunicação e teoria ator-rede: a tessitura de redes de aprendizagem via mídias ubíquas. Tese (Doutorado em Educação) - Universidade do Estado de Santa Catarina, Florianópolis, 2017.

SOARES, Ismar de Oliveira. Plano de leitura e pesquisa. In: SOARES, Ismar de Oliveira; VIANA, Claudemir Edson; XAVIER, Jurema Brasil (orgs.). Educomunicação e suas áreas de intervenção: novos paradigmas para o diálogo intercultural. São Paulo: ABPEducom, 2017. p.14-18.

SOUZA, Kamila Regina de. Os desenhos animados e a prática pedagógica educomunicativa na educação infantil: uma aventura dialógica no estágio curricular. Tese (Doutorado em Educação) - Universidade do Estado de Santa Catarina, Florianópolis, 2017. 